\title{
LA ESCRITURA COMO SUTURA SIMBÓLICA EN LA POESÍA DE FRANCISCO BRINES: ALGUNAS CALAS
}

\author{
WRITING AS SYMBOLIC SUTURE \\ IN FRANCISCO BRINES' POETRY: SOME NOTES
}

\section{Sergio ARLANDIS LÓPEZ}

Universitat de València

Sergio.arlandis@uv.es

Resumen: La poesía de Francisco Brines siempre ha sido calificada como clásica, apelando a un equilibrio que, en la mayoría de los casos, parece evidente. Partiendo de la teoría de la herida trágica como origen de la creatividad, formulada, entre otros, por Creuzer, Nietzsche, Heidegger, Jung o Durand, nos hemos acercado a su poesía tratando de mostrar si en ella se da esa reconciliación (equilibrio de base estoica) con lo creado. Análisis que nos revela una rebelión de fondo, del mismo modo que su poesía se nos define de modo similar. En consecuencia, hemos señalado qué marcos escénicos (la ciudad y la noche) son los señalados en su obra como ámbitos de tal rebelión tan poco equilibrada, tan alejada del postulado clásico que tanto la ha caracterizado. 
Abstract: The poetry of Francisco Brines has been labeled as classic, appealing to a balance that, in most cases, seems evident. Departing from the theory of the classic wound as origin of creativity, formulated, among others, by Creuzer, Nietzsche, Heidegger, Jung and Durand, I have approached Brine's poetry trying to show whether in him this reconciliation (balance of stoic basis) with the creation takes place. This analysis reveals a deep down rebellion, in the same way that his poetry is defined in a similar way. Consequently, I have pointed out the scenic frames (the city and the night) that are pointed out in his work as sphere of such little balanced rebellion, far from the classic postulate that has been one of his features.

Palabras claves: Conocimiento. Pensamiento trágico. Sutura simbólica. Desdoblamiento. Equilibrio clásico. Francisco Brines. Poesía.

Key words: Knowledge. Tragic thinking. Symbolic suture. Division. Classic balance. Francisco Brines. Poetry.

Podemos afirmar que ya casi se ha convertido en un lugar común resaltar que el origen de la escritura en Francisco Brines radica en la expresión de un conflicto con el entorno y con uno mismo, así como en la confluencia y desmarque de ambos. En consecuencia, la búsqueda - insistente- del conocimiento de ese conflicto es el eje sobre el que gira su indagación poética, aunque el resultado final sea un mensaje fatal y teñido de escepticismo (Pujante, 2004: 16). Pero para dar testimonio y expresión de ello, Brines se apoya en una peculiar visión de mundo fundamentada en una representación simbólica de la realidad, que intenta reconstruir el tiempo perdido y las emociones en la perdurabilidad del poema, imponiendo un tono reflexivo y equilibrado paradójicamente, que muchos han calificado de «clásico» (Siles, 2002: 142-128; Díez de Revenga, 2011: 19-34). A veces, ese conflicto se resuelve mediante una decidida voluntad de rebeldía; y otras, en cambio, mediante una injustificada pérdida de la inocencia y de sus dones vivificadores. Tanto de un modo como de otro, Brines se vale de mecanismos de naturaleza simbólica para poetizarlo desde esa doble óptica: por ejemplo, a través de algunos esquemas alegóricos en muchos de sus poemas (el viaje, la ascensión a la montaña, la caída, la barca del Leteo, etc.) con renovado acierto o a través de ciertos mitemas ${ }^{1}$. Y todo, dirigido hacia un evidente

1 Entendamos mitema como «sentido escondido del mito» es decir, una unidad mínima de construcción y entendimiento del mito que, en ocasiones (aunque no de manera exclusiva ni necesaria), suele identificarse con una figura o mitologema. Así lo definía Claude Lévi-Strauss (1968: 215-216), del mismo modo que más tarde lo entendieron, entre otros, Gilbert Durand (1982: 344) y Kurt Hübner (1996: 62-64). 
conflicto que le impele — consciente e inconscientemente- hacia su razón de ser como testimonio de esa dura escisión interior entre el ser y lo sido, que es la conciencia temporal.

Clave resultará, de nuevo, la aclaración de Pujante cuando nos vuelve a poner sobre la pista del origen de tal conflicto, su representación literaria y la conexión con su tiempo histórico:

En toda escritura necesaria partimos de un conflicto inconsciente que la requiere, que es la raíz de su aparición. Y ese conflicto es un conflicto humano (aestético), previo a la fragua de la obra; si bien lo detectamos en ella, desde ella (requiere del arte para su manifestación, requiere de una solución estética cuyo misterio asombra del propio autor) [...] Aunque de forma inconsciente, surge desde su realidad psíquica profunda la necesidad de reparar el objeto destruido y nace así la escritura negadora del mundo, minimizadora del mundo de su goce [...] Así la obra de Brines no solo ofrece el testimonio de una liberación moral, de una sólida consolidación ética y de una visión del ser en una igualmente sólida construcción estética de carácter personal, sino que marca un camino de salida a la angustia (Pujante, 2004: 31).

Aunque debemos apuntar que la poesía de Brines está más orientada hacia lo elemental humano que hacia cualquier circunstancia histórica con$\operatorname{creta}^{2}$. Porque en lo elemental dicen que radica, se descubre y se evidencia una profunda ruptura de la armonía existencial, una quiebra por donde deseo y realidad se disocian inexorablemente, como también ocurriera en uno

${ }^{2}$ El propio Francisco Brines se autodefine recurrentemente como un poeta de la intimidad, donde tiempo y conocimiento se viven desde un punto de vista personal, pero con un afán metafísico que le confiere un valor universal (Bousoño, 1984: 51). Sin embargo, también estamos ante una estética individual que busca la expresión de una ética en la que «esa tanteante indagación del yo en la poesía no persigue otra cosa que el conocimiento de la borrosa identidad humana, hallada en el individuo que se es. Los poetas, al hablar de sí mismos, siempre están hablando de los demás» (Brines, 1995: 41-41). No obstante, esta intimidad a la que apela Brines, enlazaría también con la opinión de José Paulino Ayuso cuando afirmaba que generacionalmente - y toda generalización peca de inexactitud, como sabemoslos del 50 apostaban por una poesía enclavada en una realidad personal ambigua, desconcertante y desconcertada, de íntimo dolor que busca trascender las meras vinculaciones colectivas para convertirse en testimonio de un yo que se «muestra escindido, en conflicto consigo mismo, en el tiempo presente o en relación con el tiempo pasado. De ahí el uso de un «tú» como antítesis identificadora del yo. El poema como espejo» (Ayuso, 1998: 49). Estaríamos, por tanto, ante una poesía que buscaría —en palabras de Vicente Aleixandre en el prólogo a la segunda edición de La destrucción o el amor (1944)— «No a lo que refinadamente diferencia, sino a lo que esencialmente une» (Aleixandre: 2002: 360). Entendemos el tiempo histórico en el primer caso, y la condición humana existencial en el segundo. 
de sus más evidentes referentes entre sus lecturas: Luis Cernuda ${ }^{3}$ (García, 2013: 382-425).

Muchos de los ensayos que tratan la reconstrucción del sentido (existencial y su reflejo en la escritura) apelan a un intento de sutura, con la intermediación de ejercicios simbólicos y simbolizados: el arquetipo de la ruptura - se afirma - está en la base del imaginario colectivo (de la humanidad) y su dotación simbólica es fecunda y continuamente actualizada (Cassirer, 1970; Givone, 1991; Ross, 1992; Kerényi, 1994: 17-44; Ortíz-Osés, 2001: 34-60). Por tanto, la radicalidad ontológica de la herida impele también a la búsqueda de formas de sutura que, si nunca recomponen la unidad rota, impliquen los fragmentos en dispersión, reunificados, por ejemplo, a través del ritual creativo ${ }^{4}$, religioso, etc.

Que tal sutura no se satisface con la propuesta de un consenso racional es evidente, puesto que el desgarro al que aludimos es pre-racional (Lanceros, 1997: 50): se impone al hombre ab initio, aunque se atienda a la postrera necesidad de racionalizarlo de muy diversos modos. Pero el hombre — quizá aquel que vislumbra la existencia de dicha herida con clarividencia artística y/o religiosa- aparece desde ese origen como «encrucijado», situado en el medio de una lucha que le precede, que es conflicto entre luz y tinieblas. A través de la creatividad, como del rezo, de la reflexión filosófica, o del ritual de la escritura el hombre es devuelto al entre, pero ya no en comunicación armónica, sino obligado a soportar y conservar el conflicto. Es decir, a re-vivirlo, como única forma de mantener la totalidad y mantenerse en ella (Elíade, 2000: 555-561). Esto explicaría por ejemplo la constante renovación de ciertos esquemas mítico-simbólicos, en cuanto

3 Cabe recordar, en todo caso, la relación constante de Brines con la obra cernudiana, no solo en la elaboración de alguna edición del poeta andaluz, como la que hiciera de Ocnos (Cernuda, 2002), sino también - y sobre todo - su discurso de ingreso en la Real Academia Española, el 21 de mayo de 2006, titulado Unidad y cercanía personal en la poesía de Luis Cernuda, donde afirmaba: «La esencia de su poesía la constituye el conflicto que se establece entre esos dos términos, ya que el deseo, en muy contadas ocasiones logra el 'acorde' con la realidad, que se muestra esquiva. Son los momentos en que el poeta alcanza «la eternidad en el tiempo». Esto se produce, o al menos allí lo encuentra Cernuda, en el amor, en la naturaleza o en el arte. Buscará el primero con escepticismo y fervor, se cobijará en los otros dos con exigencia, pero con mayor confianza» (2006b: 25). Opinión que, sin duda, cabe ponerla directamente en relación con nuestro presente estudio.

4 En este sentido me estoy haciendo eco de la siguiente afirmación de Patxi Lanceros: «la herida trágica y el conflicto [de la totalidad escindida] son los dos vectores que configuran de manera especial la escena imaginaria: aquella en la que surgen el mito, el cuento, el arte como formas privilegiadas de expresión» (1997: 55). 
testimonios estables de esa escisión primigenia ${ }^{5}$, así como su constatación de que hubo un tiempo de armonía, aunque perdida en el presente y solo recuperable — desde una justificación religiosa - a través de la muerte, pues como afirma Mircea Eliade, «la función principal del mito es revelar los modelos ejemplares de todos los ritos y actividades humanas significativas» (1999: 15-16) entre los que destacan el nacimiento y la muerte, la ruptura y su ilusión restauradora, ya que «el hombre, tal como es hoy, es el resultado directo de estos acontecimientos míticos, está constituido por estos acontecimientos [primordiales]. Es mortal, porque algo ha pasado in illo tempore [...] Pero el mito del origen de la muerte cuenta lo que sucedió in illo tempore, y al relatar este incidente explica por qué el hombre es mortal» (Eliade, 1999: 18-19). Si bien, el carácter originario y fundamental de la herida trágica es que el hombre no aparece como protagonista, sino que se ve complicado en él y a él referido: víctima siempre. Sólo en un segundo momento, como ocurre en el Génesis (3) o en el relato mitológico de Prometeo (Neumann, 1992: 67-93), el hombre reitera la escisión y su culpa, propiciando una lectura moral de la noche o del mal ${ }^{6}$.

5 Afirma Juan Villegas, respondiendo implícitamente al esquema-modelo del monomito planteado por Campbell (1991), que las estructuras artísticas —en las que encuadramos la escritura — son «plasmaciones, actualizaciones, de unas estructuras anteriores constituidas por situaciones que originaron su manifestación dentro de una cultura dada [...] las denominamos estructuras míticas, cuya vigencia no se agota con su actualización en un contexto dado» (Villegas, 1978: 53-54). Sería, visto así, una línea de sentido articulada y articulatoria (por y de) la creatividad. En cierto modo - apuntamos- concuerda con la isotopía gremasiana (Greimas, 1976) y que, desde otros planteamientos, hizo para sí la mitocrítica, al entender que dichas estructuras eran derivadas de la Einbildungskraft del ser humano, es decir, intrínseca a su capacidad creadora. Como igualmente apuntó Northorp Frye, el objetivo de la crítica mítica será el de estudiar esos principios estructurales de la propia literatura y, en particular, sus convenciones, sus géneros y sus arquetipos o imágenes recurrentes (Frye, 1967: 40) derivados todos ellos de una misma matriz de signo traumático, tal y como ya había expuesto Carl Gustav Jung (2004: 9-46) al hablar del inconsciente colectivo.

${ }^{6}$ Haciéndose eco de la intermediación del ángel en ese proceso de revelación e intermediación también entre hombre y destino, afirma Massimo Cacciari (1989: 43-44) que dicha figura constituye otra forma de creación divina que reitera, en su conflicto (ángel $v s$. demonio), tal escisión o esquema elemental de ruptura, con su implícita rebelión y, en consecuencia, su condena y maldición. Como también afirma Robert Muchembled, las «metamorfosis de la figura del Mal en nuestra cultura también hablan de la desdicha de los hombres en el seno de su sociedad» (2004: 18), de ahí que se considerara - gracias a esa culpabilidad que apuntábamos_ que el diablo fuera capaz de presentarse bajo todas las formas imaginables para el ser humano: bien como deseo, como temor, como figuras reconocibles e, incluso, como un susceptible ángel de luz. Eso sí, pagado el peaje de ese gesto primigenio, el discurso del diablo, «estuvo cada vez más referido al cuerpo humano y sobre lo que este no debía hacer» (Muchembled, 2004: 44) para que, de modo seudoplatónico, no repitiéramos nuestros actos sobre la imperfección del error. Ahora bien, siguiendo al mismo Muchembled, es cierto que el infierno es también constatación del poder supremo de castigar delegado por Dios, es decir, su inexplicable acción sobre el hombre, tanto en su condenada existencial como en su salvación y perdón (la tan señalada herida), en cierto modo porque convertía su cuerpo en el espacio privilegiado donde se iban a enfrentar 
La herida trágica reaparece en todas las oposiciones que se refieren al conflicto cosmogónico: en la inadecuación entre el hombre y su entorno, en la finitud, en la locura, en la muerte (Lanceros, 1997: 67). No obstante, el imperativo trágico que une (y a veces confunde) existencia trágica con sentimiento trágico, obliga a mantenerse en el camino, a recorrerlo en una dirección que no promete progreso, sino retorno: esquema — este- que articula, junto con la caída, la obra brinesiana en su conjunto. Pero dicho retorno, que es la senda de la decepción (desde el punto de vista trágico, frente al épico), es también el re-descubrimiento de la estancia trágica como lugar o ámbito propio del poeta y su aceptación como derrota. Hasta el mismo Brines se expresaba en estos términos al señalar que la suya era: «una moral de estirpe clásica, y que podemos denominar, justamente, de estoica. Ante una cosmovisión que siente el trascurso del vivir como una continuada pérdida, y en la que el final abocamiento es el vacío, la serena aceptación del destino adverso desde el profundo amor a la vida», y añade más adelante, «esta despedida es también la conciencia de las sucesivas pérdidas en que consiste el vivir. Asistimos a un empobrecimiento sin pausa desde la adolescencia a la vejez. Empezamos por perder la inmortalidad y, después, la inocencia» (Brines, 1995: 19-20). Desde luego, el velo de lo clásico y del equilibrio sobrevuelan sus versos, aunque no siempre sea del modo en que se ha venido señalando hasta la fecha.

La obra poética de Francisco Brines ha sido definida, en algunas ocasiones, como resultado de una insistencia teñida de cierta fatalidad (Duque Amusco, 1979: 52-74; Martín, 1997: 43-45). Esta misma insistencia se reviste - libro a libro - de una profunda unidad regida, principalmente, por dos ejes fundamentales: de un lado, una visión temporal y trágica del hombre debido a su contradictoria condición existencial; de otro, desde la consideración de la escritura como mecanismo de conocimiento, tanto de la identidad propia como del mundo aprehensible que le rodea. Por tanto, desde Las brasas hasta La última costa, nos hemos ido encontrado con el progresivo desarrollo de estos dos focos temáticos guiados, entre otras cosas, por la insistencia que define a la escritura como respuesta a los propios interrogantes de la existencia o como conflicto abierto frente al Olvido y la Nada.

Bien y Mal, dejando al hombre expuesto a los tirones de la carne y al control o autocontrol del espíritu y, por ello, volviendo a condensar significativamente una escisión irreconciliable. 
Visto así, el poema es un modo, más o menos satisfactorio, de cerrar esa herida trágica de la existencia que, insistentemente, también se abre con la memoria, por eso, «de los emocionantes escombros de la vida surge la motivación del poema» (Brines, 1995: 22) ${ }^{7}$. Una insistencia provocada, en cambio, por una esperanza de fondo, pues se espera no hallar esos signos de muerte allí donde todavía campa la vida. Pero el resultado es siempre descorazonador ya que la Nada avanza, borrando el aliento que empuja la palabra poética hacia su creación o su perdurabilidad. El poema es, por tanto, testimonio de una pérdida constante (del tiempo, de la emoción, de la experiencia e incluso de las certezas de uno mismo) como vimos, y, simultáneamente, la recreación — de ahí su insistencia - de una nueva experiencia: la del conocimiento post-sensitivo, es decir, la vivencia (o re-vivencia) desde su reflexión. Posiblemente, en el trasiego de esta voluntad de experimentar la vida desde su meditación, subyazca la implícita necesidad de transformar ese encuentro con el lector (a través de la escritura) en pura revelación de una respuesta más allá de sus propias - y personales - preguntas y emociones. Revelación, en todo caso, que pretende rebelarse, convertirse en rebelión, a pesar de todo, incluso frente a la propia aceptación de la imposible sutura simbólica.

Tal posibilidad legitima, en cierto modo, el acto poético: un motivo que lleva lo personal al umbral de lo colectivo, como dijimos. Consecuentemente, Brines se ha erigido como un gran defensor de esa función reveladora de la poesía, pues no solo nos hace más tolerantes con el otro, sino que, también, compromete al poeta con lo profundamente humano. Esto, en cierto modo, le otorga un valor ritual al propio acto de escribir, pues el poeta:

Dice y oye, a un mismo tiempo; a la vez, da y recibe el conocimiento. Esta es la función sagrada, si queremos así calificarla, del acto poético. Si el rezo produce la ilusión de la comunicación con lo desconocido, eso que en su expresión suprema llamamos Dios y que por su índole nos sobrepasa, la poesía cumple idéntico cometido con lo humano desconocido y que, por la emoción que nos produce su hallazgo, parece también que nos sobrepasa, que desciende a nosotros (Brines, 1995: 18).

${ }^{7}$ En relación con lo expuesto, resulta muy acertada la conclusión a la que llega José Andújar Almansa cuando afirma que, en Brines, «el arte nos habla de una realidad cuya duración y consistencia es superior a la de las cosas humanas. Es el espejo más cercano que el poeta posee de la inmortalidad» (2003: 113). 
En esa búsqueda de significados y sentidos lector y poeta están llamados a encontrarse (incluso a entenderse) en el doble intento del poema: la salvación del yo (la memoria) y la indagación de lo que le rodea y le conmueve o sorprende, es decir, en la razón que lleva a todas sus emociones. Claramente lo había expuesto Brines ya en el prólogo a Poemas a D.K.: «Yo parto en mi poesía de la persona que soy, y de lo que le rodea, y trato de conocer por medio de la escritura una realidad que existe y que aún no sé. Unas veces, para escribir el poema, hago hincapié en una experiencia determinada, cuyo último sentido se me revelará en la escritura, y por el que me llegará un conocimiento, una profundización en lo incógnito» (Brines, 1986: 9). Buscar una lectura más profunda de los hechos y de los pensamientos inmediatos nos acerca a un lenguaje basado en las implicaciones que los símbolos conllevan, buscando, precisamente, que ese punto de encuentro sea, cuanto menos, recíproco para que finalmente el lector, en consecuencia, sea quien consuma (y justifique) el hallazgo de nuevos caminos de identificación e interpretación de los versos. Es este valor sugerente que emana del estilo brinesiano lo que hace realmente sugerente su lectura, a pesar de la limitación temática que la caracteriza.

En gran cantidad de ocasiones, a la hora de definir su poesía, ha surgido la noción de equilibrio que hace que su obra sea calificada de clásica. Fue Antonio Colinas (1975) —y luego Andújar Almansa (2003: 81-88) — quien más hincapié hizo sobre este aspecto en su artículo titulado «Equilibrio de Francisco Brines», y en el que se nos apuntaba cómo «desde la espesa y redonda nocturnidad ${ }^{9}$ de Las brasas a la buena y bien asimilada influencia de los latinos la poesía de Brines está presidida por el equilibrio» (1975: 479). Un equilibrio, pues, visible hasta en aquellos momentos de máxima angustia y desasosiego, al menos en su resultado final. Pero curiosamente, ese «equilibrio que caracteriza toda su obra de poeta es particularmente rico cuanto traza el tema amoroso» (1975: 480), pues lejos queda su poesía «de un frío proceso racional, pero no por ello se entrega con desorden o capricho al sentir. Estamos de nuevo ante el equilibrio, soldadura ${ }^{10}$ perfecta del pensamiento y el corazón, combinación que preside la armonía» (1975: 481): afirmación que no compartimos en su totalidad, pues no siempre ocurre así en su poesía, ni existe, con tanta rotundidad, una asimilación de las

\footnotetext{
8 Aunque previamente ya había dado muchas de sus claves en su artículo «Clasicismo y culturalismo en la poesía de Francisco Brines» (Andújar Almansa, 2001: 43-58).

9 Cursiva mía.

${ }^{10}$ Cursiva mía.
} 
emociones - las amorosas principalmente - tan equilibrada, donde reina la armonía o la reconciliación, aunque sí compartamos, en todo caso, esa aceptación que José Olivio Jiménez indicó tempranamente: «El poema, en Brines, surge así como un ensamblaje perfecto, en el que una realidad sentimental y lógica, escrupulosamente objetivada, se desarrolla en esquemas sintácticos, léxicos y rítmicos de una diáfana naturalidad, los cuales rehúyen como por instinto la menor tentación de violencia o aspereza» (2001: 2930). Idea sobre la que volvería Andújar Almansa señalando, por su parte, que «lograda esa adecuación armoniosa, hallado el equilibrio, se encuentra el poema en disposición de conmover al lector» (2003: 86).

La poesía de Brines testimonia, evidencia o acaso trata de mostrarnos las consecuencias de esa escisión trágica para justificar esa mirada elegíaca (Gómez Toré, 2002; Carnero, 2013) que le caracteriza y que tantas veces se ha estudiado. Pero he aquí donde Brines se muestra especialmente original en su poética (e incluso influyente en autores posteriores) aún sin pretenderlo, como tantas veces ha manifestado por escrito: evita así el patetismo existencial para preservar - aún sin perder a Nietzsche de vista- lo eterno o, al menos, la voluntad de salvarlo, ya que a pesar de ser la Nada una verdad inapelable, la Vida, como abstracción, también lo es y solo lo estrictamente individual está condenado a su total extinción, más allá de que sea nuestra única (y reducida) manera de experimentar la propia existencia. Canto elegíaco - decíamos- que es una implícita y pública celebración de la vida: véase por ejemplo cómo en el poema «Aceptación en la terraza» (Poemas a la oscuridad) concluye:

Para ser el que fuiste
sales a la terraza, para ver
si un frío súbito derriba pronto
la plenitud del corazón. Tocas
el aire oscuro con los labios, oyes
los gritos fatigados de la calle,
la luminosa altura te estremece.
El tiempo va pasando, no retorna
nada de lo vivido:
el dolor, la alegría, se confunden
en la débil memoria,
después en el olvido son cegados.
Y al dolor agradeces
que se desborde de tu frágil pecho
la firme aceptación de la existencia.

(Brines, 2006a: 158). 
Incidamos en la aceptación de esa progresiva pérdida ante la que nada puede hacer el hombre (y el poeta), con su regreso tras el proceso revelador, expresado, como recurrentemente ocurre en su poesía, mediante el contraste sensitivo del aparecer súbito de frío o calor (tan de estirpe renacentista y de eco barroco), o del estremecimiento repentino. La memoria, pues, simula la unión de la experiencia, de la emoción que la justifica y amplifica, del tiempo pretérito que parece regresar; pero dicha memoria es también frágil y engañosa frente a la amenaza de la Nada, o como dijo en el poema «Definición de la Nada» (Insistencias en Luzbel), «hablamos desde este fiel engaño de la ficción de la palabra», pues ante esto «Lo pensáis como un frío, mas ésa es vuestra carne. / No afirma y nada niega su firme coherencia». Porque el hombre tiene la necesidad de afirmar esa existencia - aún siendo inexorable su condena dolorosa - que se aferra a su única realidad: su cuerpo. Por decirlo de una forma un tanto aleixandrinista, estaríamos ante una mística de la materia, un éxtasis que aspira, inversamente, a la plena sensación física y a su revelación última, profunda, reconciliadora. Si bien, también recuerda, en su reverso, a San Juan de la Cruz (poeta muy estimado por Brines) cuando afirmaba que «Nunca le nacen al alma turbaciones si no es de las aprehensiones de la memoria, porque, olvidadas todas las cosas, no hay cosa que perturbe la paz ni que mueva los apetitos» (1961: 193). Es un dolor, purgativo obligatoriamente, que pretende, a través de su reflexión, reafirmar una conciencia todavía vigente, todavía en estertor (calor) o en sobrecogimiento (frío), que se rebela, a pesar de todo, ante el Olvido. De este modo, resulta comprensible que en poemas como «Oscureciendo el bosque», de Poemas a la oscuridad, nos anuncie, nuevamente, esa progresiva llegada de la muerte, con su constatación evidente de que somos parte de una ruptura que nos sobrepasa y nos condena a vivir en un entre que, al mismo tiempo, nos condena a ser testigos clarividentes de ese conflicto de estirpe romántica (sin olvidar las preferencias lectoras de Brines por los poetas románticos ingleses) que le lleva a señalar la escisión entre cuerpo y alma, igual que Hörderlin apuntó la ruptura originaria entre luz y sombra:

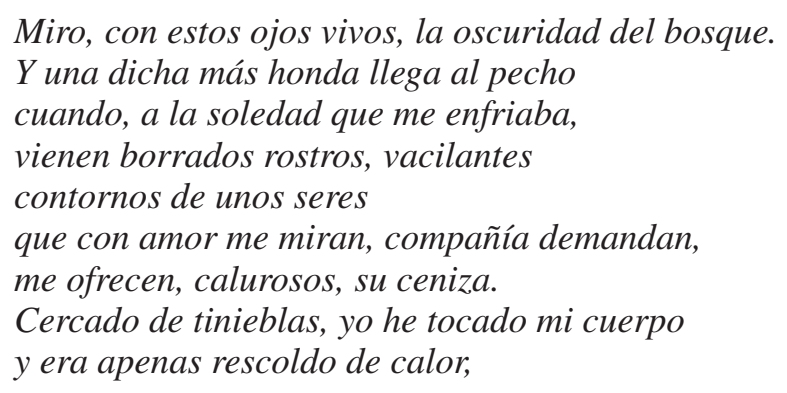


también casi ceniza.

$Y$ he sentido después que mi figura se borraba.

Mirad con cuánto gozo os digo

que es hermoso vivir.

(Brines, 2006a: 133-134).

El poeta recibe o encuentra una revelación que, si dolorosa, en parte, también consuela. En este sentido, Brines se expresa muy claramente:

La nueva realidad que, mediante las palabras hago mía, solo me puede ser dada en el texto; y se trata de una revelación que enteramente me pertenece, que no viene de fuera, sino un desvelamiento [...] Ponemos ante el espejo nuestra persona, somos en él los confidentes de nuestra propia vida, y recogemos la presencia de un extraño que nos borra, y nos suplanta, desde su mentira, con más verdad que la nuestra (Brines, 1995: 17-18).

Esa nueva realidad aspira a un equilibrio casi loyolano (ejercicios espirituales de base jesuítica), como evidencian muchos de sus textos como, por ejemplo, en la explícita referencia a San Ignacio de Loyola, en la segunda parte de Aún no, titulada «Composiciones de lugar», con un texto que define exactamente esa «recogida de la imaginación» en una reflexión de la propia identidad (en este caso, la poética) en situación. Serenidad y objetivación clarividente que se ven alteradas por las emociones que la rompen, pero que son, curiosamente, la única justificación del poema, de su revelación y su transformación, que es una verdad en sí (con ecos becquerianos) ${ }^{11}$. Pero también es un gesto de rebelión contra el olvido, porque como señala el propio Brines, «con la ayuda lúcida de la conciencia llega, con el desarrollo del poema, la manifestación de una realidad desconocida» (1995: 21), que desbanca o amplifica a la vivida, según apunta el poeta. Pero esa realidad ignota siempre nos conduce, en su obra, a la conciencia temporal trágica y a la necesidad de su sutura simbólica que le (nos) reconcilie, como se evidencia, por ejemplo, en el poema «La perversión de la mirada» (Poemas a la Oscuridad), de ahí que también afirmase:

En ocasiones el poeta ha tratado de desvelar alguna porción del misterio de la vida, de arañar el enigma a cambio de hallar el apagado resplan-

11 Fue el propio Brines quien nos pone sobre la pista de Bécquer al hacer un ejercicio de retrospección biográfica: «El primer poeta que, emocionado, leí de niño, y del que repetía de memoria poemas, fue Bécquer; pero entonces yo sólo era aprendiz de lector» (2006: 14). Más tarde David Pujante (2004: 63) se haría eco de dicha influencia, aunque ha sido muy poco estudiada por parte de la crítica brinesiana. 
dor [véase el eco prometeico que nos remite a aspectos ya apuntados aquí] de una significación. Y aparecen las palabras. Y con ellos el engaño de una aparente claridad, o tan sólo una vislumbre de luz, que para la sed del hombre, y arrastrado por la emoción estética, parece en aquel momento suficiente (1995: 15).

El equilibrio es, en términos simbólicos, defensa, sanación, aceptación de un destino (como vimos líneas arriba) que ya queda, en el acto poético, en ese entre, como lo muestra el poema, por ejemplo, «La rosa de las noches» de El otoño de las rosas. A veces se trata de un ruido o música (el poeta percibe e interpreta) que se resiste, en su abstracción, a hundirse en la nada, pues insiste en permanecer en los sentidos como también ocurre en el poema «Todavía el tiempo» de Aún no:
$Y$ sigo oyendo el tiempo, sombras
crecientes que penetran flacas
en mi cuerpo vacío,
hospicio de algún mal inacabable.
Posible es la alegría, me consuela la noche:
creía carecer de bien alguno,
y siguen devastando mi inocencia.

(Brines, 2006a: 271).

Señala muy acertadamente Gómez Toré, que la estrategia frecuente en Brines es «comenzar el poema desde un yo que contempla al mundo, para pasar repentinamente a un tú [...] convirtiendo sin previo aviso un monólogo reflexivo en diálogo [...] pues la construcción del poema responde precisamente a una constante evidencia de que la unidad entre el sujeto y la totalidad se ha roto» (2002: 44). Dicha evidencia-aportamos- es la emergente emoción (provocada, por ejemplo, por la acción rememorística) que sobrecoge al protagonista lírico en su momento máximo de revelación (es decir: de intensidad sensitiva y emocional) y, por tanto, de escisión evidenciada. Esos momentos de condensación significativa de la emoción que se reiteran en la escritura, son: por un lado, la experiencia amorosa; por otro, la visualización de la infancia y la juventud. Aún así, ante los dos (amor y tiempo pasado), Brines se muestra transgresor, tan visible ya en el poema «Hay que mecer el tallo de esta hierba» de su primer poemario Las brasas (y abre toda su obra), hasta el poema «Tentaciones al acabar la tarde» de Insistencias en Luzbel, entre muchos otros. Recuerdo y Amor, pues, quieren negar o atemperar, en su gesto transgresor, la transformación devastadora que la noche (el tiempo) ha ejercido sobre ambos, pero tanto la memoria (o escritura) como el amor, sumamente carnal y furtivo, dan la sensa- 
ción de unidad o reencuentro conciliador con el origen, de igual modo que lo señalan con mayor nitidez ${ }^{12}$, como ocurre en el poema «El extraño habitual» (Insistencias en Luzbel) que reflexiona sobre un retorno, tras aquella aventura de la vida donde «Creyó amar el instante, y solo amó su carne / solitaria, o acaso amó la carne que le amó», mientras que en el poema «El confín perpetuo» (El otoño de las Rosas) incide:

Todo fue noche, $y$ alumbraban astros

bellos e inútiles. Y envejecí

después de amar, ardiente y falso, cuerpos.

En un oscuro cuarto, con olor

de jazmines, la música venía

para curar el alma. Las palabras

hoy manchan el papel, sin son, con frío.

Sombrías son mis horas, y los años

que padecí la tierra,

pues sufrir es amar lo que nos daña.

Las pequeñas memorias de la infancia

se han perdido; por ella fue el vivir

eterna primavera y luz de sol.

Mas dudo si ha existido. Nada queda

de lo que aquí pasó: tristeza o goce.

(Brines, 2006a: 461).

Afirma el poeta que «el amor es mi inserción en el tiempo con la intensidad máxima, el deseo de mi mejor realización posible, y es también un fracaso que, aunque no tan absoluto como el de la mortalidad, puede ser más doloroso», y por ello «los aspectos felices de la vida no son contados nunca, o apenas, desde su inmediato goce; así como los momentos exultantes de amor, o la participación de la alegría, son acontecimientos prestigiosos que, en mi poesía, solo aparecen desde su pérdida» (1995: 20 y 31). Ante esto, el lenguaje se erige como única arma para manchar la Nada. Por tanto, como señaló Carole Bradford, dos fuerzas en conflicto condicionan su escritura: de un lado, un deseo constante y poderoso de superar los límites del tiempo; de otro, la convicción muy segura de que el lenguaje no le va a proporcionar la realización de su deseo (1982: 648). Este escepticismo de

12 Especialmente interesante resulta, para lo aquí apuntado, la entrevista realizada por Pedro Corral al poeta valenciano el 12 de abril de 1987 en el periódico $A B C$, donde afirma: «Si hay alguna experiencia que nos puede acercar a esa ilusión de eternidad, de instalación en la plenitud, esa es la del amor. Su existencia justifica el vivir. Aun sabiendo que es perecedera, y nosotros mortales, si imaginamos una posible Eternidad feliz, lo hacemos dándole el cuerpo de esa experiencia» (Corral, 1987: 51). 
fondo no comulga con el tan mencionado equilibrio, ya que aceptación no es resignación y en muchos casos su diferencia no queda muy clara en su poesía, quizá porque siempre se evita el sentimentalismo exacerbado, como apuntó también Andrew Debicki (1985: 30). Por ejemplo, los momentos de transgresión amorosa no se resignan a su pérdida y apuestan por su goce a pesar de todo: más bien luchan contra ella, se resisten, entran en conflicto, por así decirlo. Nos lo expone, con total rotundidad, en poemas como «Cuando yo aún soy la vida»y en «El triunfo del amor» (Aún no), donde concluye:

En la mañana solitaria, amaros, acelerad el corazón, como si fuese el solo signo de la vida. Perdurable tan solo es el vacío.

(Brines, 2006a: 226).

Nos invita — desde su entre alumbrador y sombrío- a que gocemos la vida desde la experiencia del amor. Y es que el propio poeta se había manifestado en este sentido, cuando afirmaba:

La poesía erótica, además de testimoniar experiencias, comunica manifestaciones espirituales tanto positivas como negativas. Pero hay algo que las unifica a todas, y es que siempre son el resultado de una búsqueda de intensidad. Como solo tenemos la vida, la valoramos más cuando en ella encontramos esa intensidad, y somos entonces más conscientes de su realidad, que somos nosotros mismos. Todo esto sucede menos de lo que sería deseable, porque en la vida abundan los bostezos, algo inadmisible. Es importante en mi poesía el tema erótico, porque considero que la carne es también, como el espíritu, territorio de conocimiento. La poesía busca ahí también una revelación que parece posible (Corral, 1987: 51).

Pero el amor tiene también sus propias sombras: zonas oscuras del deseo que van más allá de su descenso lumínico y el aura mediocritas estoico. El amor - apuntábamos - tiene su cuota de deseo transgresor, de insatisfecha necesidad carnal, como expresión de un desequilibrio interior (muy alejado del postulado clásico del amor idealizado), de una vaciedad que, insaciable e intenso, también crece y pasa, como la muerte, a través del pecho del hombre. Se unen ahí, precisamente, dos marcos escénico-simbólicos determinantes en su obra: la noche y la ciudad. El mismo Brines afirmó en una entrevista realizada el 21 de febrero de 2004 que «Mis poemas urbanos son más conflictivos. Allí aparece la persona menos equilibrada y de mayores intensidades... de la carne, de muchas cosas» (Ejerique, 2004: 5). Es curio- 
so - leyendo esto- que Brines defina la poesía como un acto de intensidad y lo equipare así, con la carnalidad y el deseo. La ciudad es el espacio estrictamente del hombre, de lo efímero, de lo anónimo y de lo furtivo, como tan bien analizó Gómez Toré, pues, como este nos apunta, «el espacio urbano ofrece, al abrigo de la noche, pequeños consuelos en el calor efímero pero intenso de los cuerpos» (2002: 158). Es la imperfecta creación, a nivel simbólico, del ser humano, que pretende (al modo nietzscheniano) suplantar esa ausencia de Dios, su acto cosmogónico. De ahí, pues, esa desdivinización del hombre y su aceptación como tal, visible en poemas como en «Le detuvo la noche» de Las brasas, o en «Impresión repetida» y «La ciudad ajena» (Poemas a la oscuridad). Es también espacio de un hallazgo: la realidad engañosa de lo humano frente al marco de la casa familiar que comulga en plena naturaleza en su poesía. Igual ocurre en el poema «Alba» (Aún $n o$ ), donde encontramos la decadente imagen de la ciudad, con su «salobre y húmeda, / en donde las callejas despertaban orinadas y solas» y es allí donde «se apoya aún aquel cuerpo, en una esquina, / con restos desprendidos de blasfemias y vicios» (Brines, 2006a: 273). En la ciudad, por tanto, residen las pasiones bajas o, como diría Epicuro, los deseos innecesarios e innaturales. Es el espacio de la carne escindida totalmente del alma, quizá la prueba más evidente de la ruptura metafísica: el extremo doloroso de un deseo que invade insaciablemente ante la fragilidad humana que busca el goce de la vida como aspiración perpetua pero siempre insatisfecha, de ahí, también, la insistencia y su reiteración.

La noche, por su parte, simboliza, tal y como recogen Jean Chevalier y Alain Gheerbrant (1999), Juan Eduardo Cirlot (2007) y muchos otros, «el tiempo de las gestaciones, de las germinaciones o de las conspiraciones que estallarán en pleno día como manifestaciones de vida» (Chevalier y Gheerbrant, 1999: 754). Reflejo o imagen del inconsciente, es también marco del instinto y del misterio profundo al modo platónico. Por tanto, si la poesía de Brines la hemos identificado como poética del conocimiento, es también esta experiencia transgresora un modo de adentrarse en el enigma de lo humano y, por tanto, un intento de dar luz (tenue engaño) a su inevitable condición carnal también. En la noche, surgen los ambientes degradantes, el homoerotismo o el amor mercenario, como formas un tanto marginales de mostrarnos que el hombre no solo se mueve por su afán de conocimiento o de trascendentalismo, sino también por el impulso de sus pasiones más instintivas (casi freudianas), por el eros que le impele a tener que sentir la vida desde el extremo de su más explícita levedad y de su permanente engaño. Porque el cuerpo es el umbral para el engaño y es, en cambio, nuestro modo 
de contactar con lo otro o, como llegó a afirmar Andújar Almansa, es el marco donde más nítidamente se nos invita al goce como «simple afirmación de estar vivos frente a la nada que se avecina. En Brines, la propuesta hedonista se corresponde siempre con un vitalismo afirmador [...] el placer se nos presenta como la experiencia restauradora de una plenitud perdida» (2003: 96 y 98). Modélico resulta el poema «¿Con quién haré el amor?» (Aún no):
Esta noche no habrá la mercenaria compañía, ni gestos de aparente calor en un tibio deseo. Lejos está mi casa hoy, llegaré a ella en la despierta luz de madrugada, desnudaré mi cuerpo, y en las sombras he de yacer con el estéril tiempo.

(Brines, 2006a: 233).

Por tanto, no siempre se nos invita a pensar en aquel estado de equilibrio: una emoción de temor invade al sujeto lírico que lucha contra sí mismo y su inagotable deseo, así como su necesidad de colmarlo desde la creencia de que tal cumplimiento traerá armonía interior. El resultado no es otro que un amanecer que anuncia una nueva muerte sin una previa «reconciliación» simbólica. Reflexión recurrente en su libro Aún no y fácilmente constatable en poemas como «Sombrío ardor», «Palabras para una mirada» o en «Los signos de la madrugada» que tan agudamente confirman todos y cada uno de los puntos que venimos señalando:

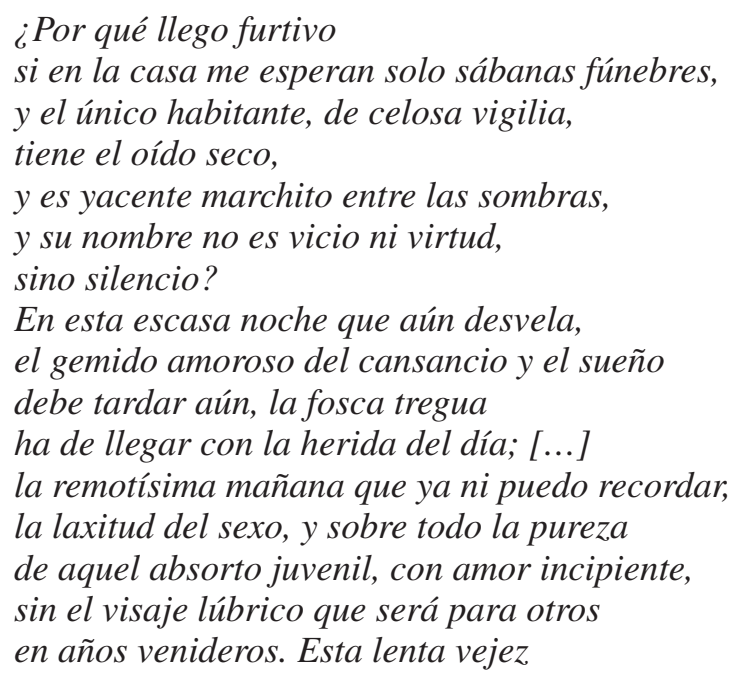


no la remedia nada; el sueño, con su máscara, va impidiendo mi muerte, pero no este derrumbe sucesivo y constante de la carne, mi floja compañera, que arroparé en las sábanas. Es acto decidido, necesario.

(Brines, 2006a: 229-230).

En verdad la noche es, en sí, la condición humana en esencia, tanto como lo es la luz que la vida arroja: somos nosotros el enigma, el conflicto, la temporalidad constatable, la herida de una armonía rota, de ahí que en el primer poema del capítulo «Poemas de la vida vieja» que abre Las brasas, con el regreso del protagonista al hogar primigenio (luminoso en la memoria) se nos diga: «Entra un hombre sin luz y va pisando / los matorrales de jazmín» e imitando cómo la sombra se adueña del paisaje, del huerto, de la vida en su rodar, continúa:

Cruza la diminuta puerta. Llegan

del campo aullidos, y una sombra fría

penetra en el balcón y es un aliento

de muerte poderoso.

(Brines, 2006a: 19).

Ciertamente la sombra es inevitable en cuanto parte de la totalidad escindida. Dicen que la rebelión romántica —momento, junto al Barroco, de importante crisis del equilibrio clásico- fue rebeldía del volumen (como bulto de sombra se identifica muy habitualmente el sujeto lírico brinesiano) frente a la forma, de la oscuridad frente a la luz, del inconsciente reprimido frente a la conciencia (Lanceros, 1997: 69): en ese conflicto, el romanticismo (y Brines es gran lector de muchos de sus autores) descubrió que bajo la superficie racional subyacía el sordo enfrentamiento de las pasiones, la encarnizada colisión de fuerzas irracionales que no se sometían al orden racional y que de ahí emanaba el auténtico impulso creador (idea que más tarde retomaría el Surrealismo). La poesía de Francisco Brines no aspira (lo que no significa que lo consiga siempre) a superar el oscurantismo que nos acecha como humanos, sino a comprenderlo, a unificarlo en armonía, y equilibrar ese fondo abrupto con su superficie racional. La conciencia trágica, en definitiva, es conciencia de destino, por eso en Palabras a la oscuridad afirma «Ama esa carne y su sombra, porque es eso a lo que llama vida. Y ama también el soplo que habrá de deshacerle para siempre, porque no existe otro destino» (Brines, 2006a: 193). En la ilusión amorosa (único destino posible para el ser humano), como en la rememorización de la escritura, el hombre juega a detener el flujo caótico de los acontecimientos mediante su 
voluntad reafirmante y de trasfondo nietzscheniano. Voluntad reordenadora por la que se intenta - afirma el poeta — «hacer súbitamente inteligible la emoción del devenir de la existencia» (Brines, 1967: 528). Reveladora rebelión diríamos la que el poeta trama tras su experiencia poetizada: perforar el olvido con la vida, llenar las emociones de su reflexión para que así se concreten y se expandan al mismo tiempo en el ejercicio de la lectura, casi como un ritual que nos restituye por momentos. Adentrarse, pues, en la sombra con una impura luz provocada tras la fricción (conflicto lo llamamos) de las palabras: alumbrar lo que somos, lo que sentimos, lo que pensamos y lo que deseamos con su total y contradictoria naturaleza, pues ahí reside el carácter originario y fundamental de lo trágico: señalar la limitación del mundo orgánico y la necesidad de ajustar dicho conocimiento. Porque vivir en el entre no solo es aspirar al equilibrio o medianía estoicos, sino también vivir en la paradoja, ser partícipe de una naturaleza existencial contradictoria, convulsa, conflictiva que, de pronto, nos asalta reveladoramente, como lo expone en el poema «El confín perpetuo», donde comienza con un
¿En dónde despertar
del sueño que corrompe?
La vida es violenta; y el espacio,
imposible. El tiempo abrió mis ojos,
y ahora cierra mi oído, borra el labio.
¿quién abre y rompe el tiempo?

No hay destino.

(Brines, 2006a: 461).

No por casualidad el motivo simbólico predominante en su obra es la caída, en cuanto testimonio de una misma escisión trágica o condena inevitable e injustificada desde su perspectiva existencial; mientras que Luzbel se erige como figura igualmente recurrente más allá del título de uno de sus libros más emblemáticos: Insistencias en Luzbel. Insistencia - con ella comenzamos - que remite a una intensidad, a un retorno sobre lo hecho: Luzbel — sin su matiz diabólico — significa «luz en las tinieblas», es decir, el personaje que encarna ese entre, ese lugar intermedio y trágico entre la luz y la sombra, como también encarna la rebelión frente al creador. Por tanto, insistir en la escritura, en la necesidad de la sutura simbólica es insistir en la emoción y no en su renuncia: es rebelarse - y no conozco equilibrio alguno en la rebeldía - frente a lo revelado y hallar —ahí la paradoja que tanto define su poesía - ese necesario equilibrio interior que evite vivir bajo el yugo del pensamiento trágico como una injusta negación del intenso don que es la vida. 


\section{REFERENCIAS BIBLIOGRÁFICAS}

ALEIXANDRE, V. (2002). Prosas completas. Madrid: Visor.

ANDÚJAR ALMANSA, J. (2001). «Clasicismo y culturalismo en la poesía de Francisco Brines». Campo de Agramante 1, 43-58.

- (2003). La palabra y la rosa. Sobre la poesía de Francisco Brines. Madrid: Alianza Ensayo.

ARLANDIS, S. (2008). «Introducción, notas y edición crítica». En Las Brasas de Francisco Brines, 9-151. Madrid: Biblioteca Nueva.

- (ed.) (2013). «Huésped del tiempo esquivo». Francisco Brines y su mundo poético. Sevilla: Renacimiento.

AYUSO, J. P. (1998). Antología de la poesía española del siglo XX. Vol II (1940-1980). Madrid: Castalia.

BOUSOÑO, C. (1984). Poesía poscontemporánea. Cuatro estudios y una introducción. Madrid: Ediciones Júcar.

BRADFORD, C. A. (1982). «El lenguaje como reflejo de la angustia del tiempo en la poesía de Francisco Brines». Cuadernos Hispanoamericanos 381, 640-648.

BRINES, F. (1966). «Notas sobre poesía». En Antología de la poesía cotidiana, A. Molina (ed.), 528-529. Madrid: Alfaguara.

- (1986). Poemas a D.K. Sevilla: El Mágico Íntimo.

- (1995). «La certidumbre de la poesía». En Selección propia, 13-53. Madrid: Cátedra.

- (2006a). Ensayo de una despedida. Poesía completa (1960-1997). Barcelona: Tusquets.

- (2006b). Unidad y cercanía personal en la poesía de Luis Cernuda. Discurso leído el día 21 de mayo de 2006 en su recepción pública. Con la contestación de D. Francisco Nieva, 9-33. Madrid: Real Academia Española-Renacimiento.

CACCIARI, M. (1989). El ángel necesario. Madrid: Visor.

CAMPBELL, J. (1991). El héroe de las mil caras. Psicoanálisis del mito. México: Fondo de Cultura Económica.

CARNERO, G. (2013). «Una tranquila espera (la poesía de Francisco Brines)». En «Huésped del tiempo esquivo». Francisco Brines y su mundo poético. S. Arlandis (ed.), 33-51. Sevilla: Renacimiento. 
CASSIRER, E. (1970). La filosofía de las formas simbólicas. México DF: Fondo de Cultura Económica.

CASTORIADIS, C. (1999). Figuras de lo pensable. Madrid: Cátedra.

CERNUDA, L. (2002). Ocnos. Sevilla: Renacimiento.

CIRLOT, J.E. (2007). Diccionario de símbolos. Madrid: Siruela.

CORRAL, P. (1987). «Entrevista a Francisco Brines: sola la experiencia del amor nos puede acercar a la ilusión de la eternidad». $A B C, 12$ de abril, 51.

CRUZ, S. J. de la (1961). Subida al Monte Carmelo. Madrid: Rialp.

CHEVALIER, J. y GREENBRANT, A. (1999). Diccionario de símbolos. Barcelona: Herder.

DEBICKI, A. (1985). Poesía del conocimiento. La generación española de 1956-1971. Madrid: Editorial Júcar.

DÍEZ DE REVENGA, F. J. (2011). «Permanencia de un clásico contemporáneo». En Encuentro de generaciones. Mirando hacia el 50, D. Pujante (ed.), 19-34. Valladolid-Nueva York: Cátedra Miguel Delibes.

DUQUE AMUSCO, A. (1979). «Algunos aspectos de la obra poética de Francisco Brines». Cuadernos Hispanoamericanos 346, 52-74.

DURAND, G. (1982). Las estructuras antropológicas de lo imaginario. Madrid: Taurus.

EJERIQUE, R. (2004). «Palabra de poeta: Brines-Marzal. Diálogo de generaciones». Blanco y Negro Cultural, 21 de febrero, 4-6.

ELIADE, M. (1999). Mito y realidad. Barcelona: Kairós.

- (2000). Tratado de historia de las religiones. Morfología y dialéctica de lo sagrado. Madrid: Ediciones Cristiandad.

FRYE, N. (1967). «Literature and Myth». En Relations of Literary Study: Essays on Interdisciplinary Contributions, J. Thorpe (ed.), 27-55. New York: Modern Language Association.

GARCÍA, M. A. (2013). «Autobiografía, conocimiento y experiencia en Francisco Brines (la sombra confortable de Luis Cernuda)». En «Huésped del tiempo esquivo». Francisco Brines y su mundo poético, S. Arlandis (ed.), 382-425. Sevilla: Renacimiento.

GIVONE, J. (1991). Desencanto del mundo y pensamiento trágico. Madrid: Visor.

GÓMEZ TORÉ, J. L. (2002). La mirada elegíaca. El espacio y la melancolía en la poesía de Francisco Brines. Valencia: Pre-Textos.

GREIMAS, A. (1976). Ensayos de semiótica poética. Barcelona: Planeta. 
HÜBNER, K. (1996). La verdad del mito. México DF: Siglo XXI.

JIMÉNEZ, J.O. (2001). La poesía de Francisco Brines. Sevilla: Renacimiento.

JUNG, C. G. (2004). «Sobre los arquetipos del inconsciente colectivo». En Hombre y sentido. Círculo Eranos III, VV. AA, 9-46. Barcelona: Anthropos.

KERENYI, K. (1994). «Hombre primitivo y misterio». En Arquetipos y símbolos colectivos. Círculo Eranos I, VV. AA., 17-44. Barcelona: Anthropos.

LANCEROS, P. (1997). La herida trágica. El pensamiento simbólico tras Hörderlin, Nietzsche, Goya y Rilke. Barcelona: Anthropos.

LÉVI-STRAUSS, C. (1968). Antropología estructural. Buenos Aires: Paidós.

MARTÍN, F. J. (1997). El sueño roto de la vida (ensayo sobre la poesía de Francisco Brines). Altea: Editorial Aitana.

MUCHEMBLED, R. (2004). Historia del diablo. Madrid: Cátedra.

NEUMANN, E. (1992). Mitos de artista. Estudio psicohistórico sobre la creatividad. Madrid: Tecnos.

ORTÍZ-OSÉS, A. (2001). «Mitologías culturales». En Los lenguajes del símbolo. Investigaciones de hermenéutica simbólica, B. Solares (ed.), 34-60. Barcelona: Anthropos.

PUJANTE, D. (2004). Belleza mojada. La escritura poética de Francisco Brines. Sevilla: Renacimiento.

ROSS, W. (1992). Nuestro imaginario cultural. Barcelona: Anthropos.

SILES, J. (2002). «Francisco Brines: un clásico viviente». Nueva Revista de Política, Cultura y Arte 80, 142-148.

VILLEGAS, J. (1978). La estructura mítica del héroe en la novela del siglo $X X$. Barcelona: Planeta.

Recibido el 15 de mayo de 2013.

Aceptado el 19 de septiembre de 2013. 
